\title{
PRODUTIVIDADE E QUALIDADE DE RAÍZES DE RABANETE CULTIVADAS SOB DIFERENTES FONTES RESIDUAIS DE MATÉRIA ORGÂNICA
}

\author{
Giovani Donizete Bonela ${ }^{*}$, Willian Pereira dos Santos², Edgar Alves Sobrinho ${ }^{3}$, Ednilson Jorge da Costa
} Gomes $^{4}$

\begin{abstract}
RESUMO - Mudanças no hábito de consumo da população em busca de uma alimentação mais saudável exige maiores cuidados para se produzir de forma limpa e sustentável. O rabanete (Raphanussativus L.), apesar de ser uma cultura olerácea consumida em menor escala, vem se destacando como uma alternativa de cultivo promissora para os olericultores do país. O uso isolado ou combinado de fertilizantes orgânicos é uma opção de adubação para uma produção mais saudável e menos agressiva ao meio ambiente. Nesse sentido, a produção sequencial de olerícolas em uma mesma área, pode aumentar o teor de matéria orgânica no solo, viabilizando cultivos subsequentes sem a necessidade de uma nova adubação. Com o objetivo de avaliar a produtividade e a qualidade das raízes de rabanete em cultivo subsequente de alface produzidas com adubação orgânica foi conduzido um experimento no campo experimental da Universidade Estadual de Goiás, Câmpus de IpameriGO, em delineamento experimental de blocos casualizados, em esquema fatorial 3 x 4, com 4 repetições, tendo como fatores as cultivares de rabanete (RedJewel F1; Variedade n 25 e a cv. Vip Crimson) e residuais de fontes de matéria orgânica utilizadas para o cultivo de alface: (testemunha sem matéria orgânica, esterco bovino, cama de aviário, esterco de suíno). As variáveis quantitativas analisadas foram: PT (Peso total das plantas); MFF (Massa fresca das folhas); MSF (Massa seca das folhas); NF (Número de folhas por planta); CP (Comprimento do caule); DR (Diâmetro da raiz); MFR (Massa fresca da raíz) e MSR (Massa seca da raiz). Foram determinadas as porcentagens de raízes rachadas e isoporizadas levando em consideração as plantas colhidas dentro da área útil para a determinação dos parâmetros qualitativos. Não houve correlação positiva entre as cultivares estudadas sob os diferentes tratamentos. O efeito residual de diferentes fontes de adubos orgânicos não foi satisfatório para a produção de rabanete em cultivo sucessivo de alface.
\end{abstract}

Palavras chave: adubação alternativa, Raphanus sativus L., sucessão de cultivo, sustentabilidade.

\section{PRODUCTIVITY AND QUALITY OF RADISH ROOTS CULTIVATED UNDER DIFFERENT RESIDUAL SOURCES OF ORGANIC MATTER}

\begin{abstract}
Changes in the habit of consuming the population in search of a healthier diet requires greater care to be produced in a clean and sustainable way. Radish (Raphanussativus L.), although it is an oleraceous crop consumed in a smaller scale, has been standing out as a promising crop alternative for the olericultores of the country. The isolated or combined use of organic fertilizers is an option of fertilization for a healthier production and less aggressive to the environment. In this sense, the sequential production of olive groves in the same area can increase the organic matter content in the soil, enabling subsequent crops without the need for a new fertilization. In order to evaluate the productivity and quality of radish roots in subsequent cultivation of lettuce produced with organic fertilization, an experiment was conducted in the experimental field of the State University of Goiás, Câmpus de Ipameri-GO, in an experimental design of randomized blocks in (Red Jewel F1, Variety $n^{\circ} 25$ and Vip Crimson) and residual of organic matter sources used for lettuce cultivation: (control without matter Organic, cattle manure, aviary bed, pig manure). The quantitative variables analyzed were PT (total weight of plants); MFF (Fresh leaf mass); MSF (Dry leaf mass); NF (Number of
\end{abstract}

\footnotetext{
${ }^{1}$ Eng. Agr., M.Sc., Professor da UEG. *giovanibonela@bol.com.br

${ }^{2}$ Acadêmico do curso de agronomia da UEG. willian.agroueg@ outlook.com

${ }^{3}$ Acadêmico do curso de agronomia da UEG. edgard_aas @ hotmail.com

${ }^{4}$ Acadêmico do curso de agronomia da UEG. ednilsonvest@ hotmail.com
} 


\begin{abstract}
leaves per plant); CP (stem length); DR (Root diameter); MFR (Fresh Root Pasta) and MSR (Root Dry Pasta). The percentages of cracked and isoporate roots were determined taking into consideration the plants harvested within the useful area for the determination of the qualitative parameters. There was no positive correlation between the cultivars studied under the different treatments. The residual effect of different sources of organic fertilizers was not satisfactory for the production of radish in successive lettuce cultivation.
\end{abstract}

Keywords: alternative fertilization, Raphanus sativus L., successive cultivation, sustainability.

\section{INTRODUÇÃO}

O rabanete (RaphanusSativus L.) pertence a família das Brassicaceaes e é originária da região mediterrânea (Rodrigues et al., 2013). Esta cultura olerácea de menor expressividade no mercado nacional (Puliti et al., 2009) é cultivado em muitas propriedades de pequeno porte dos cinturões verdes das grandes cidades (Oliveira et al., 2010), pois o seu cultivo possibilita um retorno financeiro rápido, com obtenção de renda no período entre duas outras culturas de ciclo mais longo (Cardoso \& Hiraki, 2001; Matos et al., 2015).

Atualmente são exigidos produtos isentos do uso de insumos sintéticos e defensivos químicos na garantia de qualidade de vida aos produtores e consumidores, agredindo menos o meio ambiente e o ser humano. Portanto, a utilização de insumos naturais, como os estercos bovinos e biofertilizantes, deve ser estimulada tanto na pulverização das plantas como diretamente aplicados nos solos (Maia Filho et al., 2010). As hortaliças, em sua maioria, necessitam de grandes aportes de nutrientes em períodos de tempo relativamente curtos. Esse aporte nas hortaliças tuberosas é bastante significativo tanto para o crescimento da parte aérea quanto para o desenvolvimento de seu produto principal, a raiz.

A forma tradicional de suprimento nutricional desta olerácea tem sido através do uso de fertilizantes químicos. No entanto, em função dos elevados custos dos adubos minerais associados aos problemas de contaminação do solo e dos lençóis freáticos tem se buscado formas alternativas para suprir essas necessidades (Embrapa, 2013).

De acordo com Silva et al. (2016) o emprego de técnicas agroecológicas e que não agridem o meio ambiente vem possibilitando os agricultores, principalmente os de base familiar a alcançar um mercado de produtos diferenciados, notadamente pela eliminação do uso de adubos e defensivos sintéticos ao passo que insumos localmente disponíveis assumem papel preponderante na formação desse agrossistema. A adubação orgânica contribui para o aumento da CTC (Capacidade de Troca Catiônica) do solo, regula a temperatura, além de estimular a atividade microbiana (Oliveira et al., 2015). Entretanto para que a mesma seja eficaz, há a necessidade de aplicações de quantidades elevadas podendo onerar os custos, além de promover aumento dos teores no solo, e que pode ser utilizado por plantas de ciclo curto em cultivos subsequentes, evitando desequilíbrios nutricionais e até mesmo a contaminação do solo.

Filgueira (2008) ressalta que numa sucessão de culturas oleráceas, é primordial estimar o efeito residual das adubações anteriormente aplicadas, já que é impossível fornecer os nutrientes na medida exata para atender, tão somente, à demanda da cultura visada. Segundo Oliveira et al. (2015), são encontrados na literatura resultados promissores através do cultivo de hortaliças sucedentes a adubação verde, como os publicados por Perin et al. (2004) e Linhares et al. (2011). Essa prática traz benefícios para o pequeno produtor, uma vez que em decorrência da gradativa decomposição dessas plantas favorecerá uma maior produção de fitomassa e ciclagem de nutrientes, com alguns nutrientes estando disponíveis no solo (Linhares et al., 2011), e não sendo necessário a realização de uma nova adubação, reduzindo as despesas na produção e possibilitando resultados satisfatórios, principalmente em culturas de ciclo curto, como no caso do rabanete. No entanto no processo produtivo atual de hortaliças, usualmente se faz a aplicação de adubos orgânicos originários da criação de animais, como bovinos, suínos e aves, e de acordo com sua relação C/N (Carbono/ Nitrogênio) poderá ter um período prolongado para sua mineralização, favorecendo assim a cultura subsequente a dubação. Há, portanto, escassez de pesquisas que retratam o uso residual da adubação orgânica para culturas subsequentes e que podem contribuir para a sustentabilidade do processo produtivo de olerícolas no Brasil. Diante destes fatos, objetivouse com este trabalho, avaliar o desenvolvimento, a produtividade e a qualidade das raízes de rabanete, 
sob diferentes fontes residuais de matéria orgânica em sucessão ao cultivo de alface.

\section{MATERIAL E MÉTODOS}

O experimento foi conduzido na Universidade Estadual de Goiás, Campus de Ipameri-GO, situada a $17^{\circ} 46^{\prime} 30,3^{\prime \prime}$ latitude Sul, $48^{\circ} 19^{\prime} 15,6^{\prime \prime}$ 'de longitude Oeste e altitude de aproximadamente 800 metros. O clima de Ipameri é classificado como Aw, Tropical com estação seca no inverno, segundo Köppen. A temperatura média é de $25^{\circ} \mathrm{C}$, com umidade relativa média do ar variando de $58 \%$ a $81 \%$ e precipitação pluviométrica anual de $1.447 \mathrm{~mm}$, sendo que cerca de $80 \%$ das chuvas ocorrem nos meses de dezembro, janeiro e março e o restante se distribui, principalmente, nos meses de outubro, novembro e fevereiro (Alvares, 2013).

O solo da área, segundo a atual nomenclatura do Sistema Brasileiro de Classificação de Solos (Embrapa, 2013), é um Latossolo Vermelho - Amarelo Distrófico com textura areno-argilosa. A análise química do solo onde foi instalado o experimento apresentou na camada de $0-20 \mathrm{~cm}, \mathrm{pH}=5,6 ; \mathrm{P}=17,9 \mathrm{mg} / \mathrm{dm}^{-3} ; \mathrm{K}=0,36 \mathrm{Cmolc} /$ $\mathrm{dm}^{-3} ; \mathrm{Al}=0,40 \mathrm{Cmolc} / \mathrm{dm}^{-3} ; \mathrm{Ca}=1,53 \mathrm{Cmolc} / \mathrm{dm}^{-3} ; \mathrm{Mg}=$ $0,54 \mathrm{Cmolc} / \mathrm{dm}^{-3} ; \mathrm{H}+\mathrm{Al}=2,3 \mathrm{Cmolc} / \mathrm{dm}^{-3} ; \mathrm{CTC}=4,74$ Cmolc $/ \mathrm{dm}^{-3} ; \mathrm{V}=51,27 \% ; \mathrm{M} . \mathrm{O}=3,1 \mathrm{~g} / \mathrm{kg}$. O solo foi corrigido com calcário dolomítico (PRNT 90\%) e incorporado com grade aradora na camada de $20 \mathrm{~cm}$, de modo a atingir saturação por bases de $80 \%$ segundo a recomendação de Alvarez e Ribeiro (1999).

Para o cultivo da alface que antecedeu a cultura do rabanete foram utilizados, um tratamento controle como testemunha (sem adubação orgânica); 30 t/ha de cama de frango, $60 \mathrm{t} / \mathrm{ha}$ de esterco bovino e $80 \mathrm{t} /$ ha de esterco de suíno, as doses dos adubos orgânicos utilizados foram balanceadas de acordo a quantidade de Nitrogênio de cada um (Tabela 1). Não foi utilizado nenhuma fonte de adubo mineral.
A colheita das cultivares de alface foi realizada no dia 5 de janeiro de 2016. A semeadura do rabanete foi realizada no dia 11 de janeiro, utilizando o delineamento experimental de blocos casualizados, em esquema fatorial $3 \times 4$, com quatro repetições, tendo como fatores as cultivares de rabanete (RedJewel F1; Variedade $\mathrm{n}^{\circ} 25$ e a cv. Vip Crimson) e residuais de fontes de matéria orgânica (testemunha sem matéria orgânica, esterco bovino, cama de aviário, esterco de suíno). As parcelas compreenderam uma área de 1,20 x 1,20 m, perfazendose um total de $1,44 \mathrm{~m}^{2}$, contendo quatro linhas longitudinais espaçadas com $0,30 \mathrm{~cm}$ entre linhas, sendo que as linhas laterais foram consideradas como bordadura. O desbaste foi realizado 10 dias após a germinação adequando-se as plantas ao espaçamento de $0,30 \mathrm{x}$ $0,08 \mathrm{~m}$, com 15 plantas por fileira, perfazendo-se um total de 60 plantas por parcela. A irrigação foi por aspersão, mantendo a umidade do solo próximo à capacidade de campo, suprindo todas as suas necessidades hídricas de acordo com o seu desenvolvimento. O controle de plantas infestantes foi realizado por capinas manuais e não foi utilizado nenhuma fonte de adubação de cobertura. Os dados meteorológicos como, temperatura máxima, mínima e média, precipitação pluviométrica foram registrados de acordo com o Inmet (2016), (Tabela 2).

A colheita foi realizada 30 dias após a semeadura, coletando-se 10 plantas, dentro da área útil por parcela. Destas foram realizados o peso total das plantas, logo após a colheita em uma balança de precisão com duas casas decimais. As folhas foram destacadas das raízes para contabilização do número de folhas de cada planta. As folhas foram lavadas e colocadas para secar em estufa com circulação forçada de ar até atingirem peso constante, para a determinação da massa seca das folhas. As raízes foram pesadas e em seguida realizada a aferição do diâmetro médio das raízes com o auxílio de um paquímetro digital. Estas também foram lavadas e

Tabela 1 - Características químicas dos adubos orgânicos utilizados no experimento. UEG, Ipameri-GO, 2016

\begin{tabular}{|c|c|c|c|c|c|c|c|}
\hline \multicolumn{8}{|c|}{ Características químicas } \\
\hline $\begin{array}{l}\text { Adubos } \\
\text { Orgânicos }\end{array}$ & $\begin{array}{l}\text { C. org. } \\
\text { (dag.kg1) }\end{array}$ & $\begin{array}{c}\text { N total } \\
\left(\text { dag. } \mathrm{kg}^{1}\right)\end{array}$ & $\begin{array}{c}\mathrm{C} / \mathrm{N} \\
\left(\mathrm{dag} \cdot \mathrm{kg}^{1}\right)\end{array}$ & $\begin{array}{c}\text { P total } \\
\left(\text { dag. } \mathrm{kg}^{1}\right)\end{array}$ & $\begin{array}{c}\text { K total } \\
(\text { dag.kg1) }\end{array}$ & $\begin{array}{l}\text { Ca total } \\
\left(\text { dag. } \mathrm{kg}^{1}\right)\end{array}$ & $\begin{array}{c}\text { Mg total } \\
\left.\text { dag. } \mathrm{kg}^{1}\right)\end{array}$ \\
\hline Cama de frango & 30,6 & 3,2 & 9,6 & 3,3 & 2,6 & 4,0 & 0,7 \\
\hline Cama de suíno & 22,5 & 2,6 & 8,6 & 2,8 & 2,7 & 2,6 & 0,8 \\
\hline Esterco bovino & 28,2 & 1,5 & 18,8 & 1,3 & 1,7 & 1,0 & 0,6 \\
\hline
\end{tabular}

C.org: Carbono orgânico; N Total: Teor total de nitrogênio dos materiais utilizados; C/N: Relação Carbono e Nitrogênio dos materiais; $\mathrm{P}, \mathrm{K}, \mathrm{Ca}, \mathrm{Mg}$ : Teores dos nutrientes. Fonte: dados da pesquisa. 
colocadas em estufa com circulação forçada de ar, realizando-se assim o peso secodas raízes. Para avaliação dos dados qualitativos foram determinadas a porcentagem de raízes rachadas e isoporizadas levando em consideração as plantas colhidas dentro da área útil para a determinação dos parâmetros quantitativos.

Os resultados foram submetidos à análise de variância pelo teste $\mathrm{F}(\mathrm{p}<0,05)$ e médias comparadas pelo teste de Tukey.

\section{RESULTADOS E DISCUSSÃO}

Não houve correlação positiva entre as cultivares de rabanete analisadas e o residual dos adubos orgânicos aplicados para o cultivo de diferentes cultivares de alface (Tabela 3 ).

As cultivares RedJewel F1 e $\mathrm{N}^{\circ} 25$ foram as que obtiveram melhores desempenhos em todas as variáveis analisadas (Tabela 3).

Com relação ao peso total das raízes após a colheita (PT), a cultivar cv. RedJewel foi a que apresentou melhores resultados com média de 7,68 gramas, não se diferenciando estatisticamente da cv. 25, com médias de 6,28 gramas, sendo que a cv. Vip Crimson, foi inferior as duas primeiras com média de 5,09 gramas (Tabela 4).
Em relação a Massa Fresca (MFF) e Massa Seca das Folhas (MSF), não houve diferenças significativas para as três cultivares estudadas (Tabela 4). Em ensaio realizado por Souza et. al (2012), onde avaliaram diferentes fontes de adubação orgânica (testemunha, esterco bovino, cama de frango, cama de suínos e húmus), em um Argissolo Vermelho de textura arenosa, os mesmos verificaram em primeiro cultivo, incrementos significativos para MFF e MSF, no qual o esterco bovino promoveu melhores resultados para todas as variáveis analisadas.

Resultados contrastantes foram observados Bonela et. al (2015), quando avaliaram diferentes fontes de matéria orgânica para o cultivo de alface, tendo como destaque as fontes de cama de frango e cama de suíno.

Esta variação está diretamente ligada ás característica químicas dos materiais utilizados, assim como a influência da relação Carbono e Nitrogênio. No entanto para este estudo, utilizando o residual destas adubações orgânicas, não houve correlação positiva.

Pedó (2010) avaliou o crescimento de três cultivares de rabanete (Vip Crimson; Vermelho Redondo; Cometo), e observaram que a cultivar Vip Crimson apresentou maior geração de matéria seca, ou seja $15,9 \mathrm{~g} \mathrm{~m}^{-2}$ aos 28 dias; porém a cultivar Vermelho Redondo mostrou

Tabela 2 - Dados meteorológicos do período experimental - UEG, Ipameri-GO, 2016

\begin{tabular}{lccccc}
\hline Mês/Ano & T. máx. $\left({ }^{\circ} \mathrm{C}\right)$ & T. min. $\left({ }^{\circ} \mathrm{C}\right)$ & T. méd. $\left({ }^{\circ} \mathrm{C}\right)$ & UR $(\%)$ & Precipitação(mm) \\
\hline Novembro/15 & 32,5 & 21,2 & 26,8 & 69,8 & 212,4 \\
Dezembro/15 & 31,4 & 20,7 & 26,0 & 72,4 & 176,6 \\
Janeiro/16 & 29,4 & 21,2 & 25,3 & 81,4 & 301,4 \\
Fevereiro/16 & 31,9 & 20,5 & 26,2 & 75,4 & 180,4 \\
Média & 31,3 & 20,9 & 26,0 & 74,7 & - \\
\hline
\end{tabular}

T. máx (Tempertura máxima); T. min. (Temperatura mínima); T. méd (Temperatura média); UR (Umidade Relativa). BDMEP - INMET: Banco de dados meteorológicos para ensino e pesquisa; Instituto Nacional de Meteorologia.

Tabela 3 - Produtividade de cultivares de rabanete em função dos diferentes tipos de residuais de material orgânico utilizado no cultivo de alface. UEG, Ipameri-GO, 2016

\begin{tabular}{lccr}
\hline \multirow{2}{*}{ Residuais de material orgânico } & \multicolumn{3}{c}{ Cultivares } \\
\cline { 2 - 4 } & Vip Crimson & $\mathrm{N}^{\mathbf{0}} 25$ & RedJewel F1 \\
\hline Testemunha & $40,01 \mathrm{Ab}$ & $48,59 \mathrm{Aab}$ & $62,93 \mathrm{Aa}$ \\
Esterco bovino & $44,98 \mathrm{Ab}$ & $54,11 \mathrm{Aab}$ & $52,33 \mathrm{Aa}$ \\
Esterco de frango & $18,66 \mathrm{Ab}$ & $31,07 \mathrm{Aab}$ & $70,09 \mathrm{Aa}$ \\
Esterco de suíno & $31,44 \mathrm{Ab}$ & $39,25 \mathrm{Aab}$ & $71,55 \mathrm{Aa}$ \\
\hline
\end{tabular}

Médias seguidas da mesma letra maiúscula na mesma linha não diferem entre si, médias seguidas da mesma letra minúscula na mesma coluna não difere entre si, pelo teste de Tukey a $5 \%$ de probabilidade. 
Tabela 4 - Peso total das plantas (PT), massa fresca das folhas (MFF), massa seca das folhas (MSF), número de folhas por planta (NF), comprimento médio das plantas (CP), diâmetro médio da raiz (DR), matéria fresca da raiz (MFR), matéria seca da raiz (MSR), de cultivares de rabanete em função do residual de diferentes adubos orgânicos aplicados para cultivo de alface. UEG, Ipameri-GO, 2016

\begin{tabular}{lcccccccc}
\hline Cultivar & PT $(\mathrm{g})$ & MFF $(\mathrm{g})$ & MSF $(\mathrm{g})$ & $\mathrm{N}^{\circ}$ Folhas & $\mathrm{CP}(\mathrm{cm})$ & DR $(\mathrm{cm})$ & MFR $(\mathrm{g})$ & $\mathrm{MSR}(\mathrm{g})$ \\
\hline $\mathrm{N}^{\circ} 25$ & $6,28 \mathrm{ab}$ & $4,35 \mathrm{~b}$ & $1,14 \mathrm{~b}$ & $2,16 \mathrm{ab}$ & $3,93 \mathrm{ab}$ & $1,09 \mathrm{ab}$ & $3,86 \mathrm{ab}$ & $0,81 \mathrm{ab}$ \\
Vip Crimson & $5,09 \mathrm{~b}$ & $3,69 \mathrm{~b}$ & $0,97 \mathrm{~b}$ & $1,86 \mathrm{~b}$ & $3,27 \mathrm{~b}$ & $0,86 \mathrm{~b}$ & $2,92 \mathrm{~b}$ & $0,62 \mathrm{~b}$ \\
RedJewel F1 & $7,68 \mathrm{a}$ & $4,89 \mathrm{~b}$ & $1,25 \mathrm{~b}$ & $2,34 \mathrm{a}$ & $4,15 \mathrm{a}$ & $1,37 \mathrm{a}$ & $5,18 \mathrm{a}$ & $1,07 \mathrm{a}$ \\
CV\% & 36,90 & 30,45 & 35,62 & 25,79 & 24,73 & 27,96 & 27,30 & 35,75 \\
Média & 6,35 & 4,31 & 1,12 & 2,12 & 3,78 & 1,10 & 3,99 & 0,84 \\
\hline
\end{tabular}

Médias seguida da mesma letra não diferem entre se pelo teste de TuKey a nível de $5 \%$ de probabilidade.

maior desenvolvimento no índice de área foliar. Neste estudo todas as cultivares se igualaram estatisticamente para as duas variáveis.

Para o rendimento de massa de matéria seca das raízes, Paiva et al. (2013), verificaram maiores rendimentos para o residual com adubação verde de $30 \mathrm{t} / \mathrm{ha}$. Resultados inferiores foram encontrados Pereira et al. (2011) e superiores por Oliveira et al. (2005). Para este experimento nesta época, o resultado foi em média $98 \%$ inferior a produção de matéria seca dos anteriores.

Acv. Red Jewel apresentou maior número de folhas por plantas (NF), não se diferenciando da cv. $\mathrm{N}^{\circ} 25$, que por sua vez também não se diferenciou da cv. Vip Crimson, apresentando médias de 2,3;2,2 e 1,9 folhas por planta, respectivamente (Tabela 4 ).

O número de folhas está diretamente ligado aos teores de nutrientes disponíveis no solo e principalmente com as características morfológicas de cada cultivar, podendo ainda apresentar variações, de acordo com a época de cultivo. De acordo ainda com Linhares et al. (2010), número de folhas é importante, tendo vista que este órgão no vegetal é o local onde ocorre o processo bioquímico (fotossíntese) responsável pela produção de fotoassimilados que serão enviados para os órgãos produtivos da planta. Cecconello (2016) verificou que a variação nas doses de vermicomposto não influenciaram estatisticamente no NF de rabanete. No entanto, Linhares et al. (2010), estudando o efeito residual das doses e tempos de decomposição de jitirana (Merremiaaegyptia (L) Urb.) na produtividade do rabanete, observaram um aumento de cerca de uma folha por planta de rabanete, variando as doses entre 5,4 e 15,6 $\mathrm{Mg} \mathrm{ha}^{-1}$ incorporadas ao solo.
Neste caso, o cultivo foi realizado no período de verão, com temperaturas elevadas e alto índice de precipitação (Tabela 2), o que colaborou para o aumento na incidência de doenças foliares, diminuindo assim o número de folhas no momento das avaliações.

Para o comprimento das plantas, também não houve diferenças significativas entre as cultivares Red Jewel, com médias de $4,15 \mathrm{~cm}$ e cv. $\mathrm{N}^{\circ} 25, \operatorname{com} 3,93 \mathrm{~cm}$, sendo que está última não foi diferente estatisticamente da cv. Vip Crimson, com 3,27 cm (Tabela 4). A cultivar de rabanete que apresentou maior diâmetro médio de raízes foi a Red Jewel com $1,37 \mathrm{~cm}$, não se diferenciando da $\mathrm{cv}$. $\mathrm{N}^{\circ} 25 \mathrm{com} 1,09 \mathrm{~cm}$ e que por sua vez não foi diferente da cv. Vip Crimson (Tabela 4).

Estes resultados foram bem inferiores aos encontrados por (Oliveira et al., 2005; Salgado et al., 2006; Vittil et al., 2007), os quais obtiveram média de $3,5 \mathrm{~cm}$ de diâmetro de raízes de rabanete quando cultivadas sob adubação orgânica.

O crescimento e desenvolvimento de raízes de rabanete está relacionado com o teor de matéria orgânica do solo e principalmente com suas características físicas, como teores de argila, que influenciam diretamente na porosidade, proporcionando melhores rendimentos. Paiva (2013), avaliou o efeito residual de de diferentes dosagens de restos vegetais espontâneos encontrados na Caatinga, e verificaram que o residual da adubação orgânica com a jitirana (Marremia aegyptia L.) em cultivo de cenoura e coentro, incorporada ao solo, na dosagem de $30 \mathrm{t} / \mathrm{h}$ a foi a que promoveu maior incremento de diâmetro de raiz, atingindo valores máximos de $4,6 \mathrm{~cm}$ para a cultivar Crimson Gigante. A velocidade de decomposição entre os diferentes tipos de adubos verdes utilizados contribui para uma maior porcentagem de 
residual orgânico, proporcionando efeitos significativos para o crescimento e desenvolvimento de raízes de rabanete. Os resultados relatados por Linhares (2010), de diâmetro médio de raiz foram de $26,8 \mathrm{~cm}$, também utilizando como fonte a adubação verde com jitirana, em diferentes tempos para a sua decomposição, mostraram-se ainda sim, superiores aos encontrados neste experimento, com média entre as cultivares avaliadas de $1,10 \mathrm{~cm}$ (Tabela 3), porém esta superioridade está atribuída a avaliação em primeira aplicação do material orgânico e não do residual, como no presente estudo.

O alto índice de precipitação no período de cultivo, $334 \mathrm{~mm}$, segundo Inmet (2016), também provocou aumento da compactação da camada superficial do solo, o que pode ter influenciado no crescimento das raízes, diminuindo assim o seu diâmetro.

Para a massa fresca (MFR) e massa seca da raiz (MSR), também não foram encontradas diferenças significativas entre as cultivares Red Jewel e $\mathrm{N}^{\mathrm{o}} 25$, sendo que esta última também não se diferenciou da cv. Vip Crimson para as mesmas variáveis.

Quanto à qualidade das raízes produzidas, o efeito do residual não proporcionou a produção de raízes com características comerciais desejáveis. A cv. Vip Crimson, foi a que apresentou a maior porcentagem de raízes com padrões não comerciais, $(78,8 \%)$, sendo que apenas $(13 \%)$ do total das raízes colhidas, apresentara padrão comercial mínimo desejável. Para esta cultivar o tratamento que proporcionou maior porcentagem de raízes não comerciais foi o de residual de cama de frango $(100 \%)$, seguido pelo de residual de cama de suíno $(91,5 \%)$, esterco bovino $(75 \%)$ e testemunha $(49,7 \%)$.

A cv. $N^{\circ} 25$, apresentou $(56,1 \%)$ de raízes não comerciais e apenas (31\%) atingiram o padrão mínimo de mercado. O tratamento que apresentou a maior porcentual de raízes não comerciais foi o de residual de cama de suíno $(81,2 \%)$, seguido pelos de cama de frango e testemunha, ambos com $(58,2 \%)$, sendo que o tratamento com residual de esterco bovino apresentou apenas (25\%), este por sua vez, apresentou o maior percentual de raízes com padrões de mercado para esta cultivar (41,5\%). Acv. $\mathrm{N}^{\circ} 25$ foi a que apresentou maior percentual de raízes com rachaduras, com média de $(10,3 \%)$, sendo o tratamento com residual de esterco bovino o que apresentou maior quantidade de raízes rachadas $(24,7 \%)$. Já a cv. Red Jewel F1, foi a que apresentou maior percentual de raízes com padrões comerciais $(43,4 \%)$, sendo o tratamento com residual de adubação com cama de frango, o que apresentou melhores resultados para esta cultivar $(49,7 \%)$.

Para todas as cultivares o tratamento com residual de esterco bovino foi o que apresentou melhores resultados, com (45\%) de raízes comerciais seguido pela testemunha $(36,4 \%)$, residual de cama de frango $(25,8)$ e residual com cama de suíno $(21,9 \%)$, sendo este último o que apresentou maior percentual de raízes não comerciais com $(74,2 \%)$. Observa-se que, a relação $\mathrm{C} / \mathrm{N}$ do esterco de bovino é praticamente duas vezes maior do que as do esterco de suíno e de frango (Tabela 1), o que reforça a hipótese de sua mineralização ser mais lenta, e consequentemente, apresentar menor disponibilização do N. De acordo com Brito et al. (2005), citado por Peixoto Filho et al. (2013), a velocidade de decomposição, e conseqüente mineralização dos resíduos orgânicos interferem diretamente na disponibilidade de nutrientes para as plantas sobremaneira para aquelas de ciclo curto, como a alface e o rabanete.

Sampaio (2007), constatou que o esterco bovino causou imobilização de nutrientes do solo no primeiro mês após sua incorporação; depois deste período a liberação aumentou progressivamente atingindo as maiores quantidades entre três e seis meses após a incorporação.

Peixoto Filho (2013), verificou que a produção de matéria seca, produtividade e número de folhas de alface, foram superiores nos tratamentos com esterco de frango apenas no primeiro cultivo; entretanto, nos cultivos seguintes este foi sendo superado pelos outros estercos. Estes dados reforçam a hipótese de que o residual de esterco bovino é mais eficiente para a nutrição das plantas do que a sua adubação em primeiro ciclo.

Quanto ao percentual de rachaduras vários fatores podem ter contribuído. A alta incidência de rachaduras e a não formação das raízes, verificada no presente trabalho, também pode ser atribuída às oscilações hídrica e térmica no solo, advindas de elevadas temperaturas registradas em alguns dias (Tabela 2) e à falta de cobertura morta sobre o solo, favorecendo o rápido secamento da camada superficial do solo. Segundo Filgueira (2008), as oscilações hídricas acarretam rachaduras nas raízes de rabanete. De acordo com Pinheiro et al. (2012) o rabanete necessita de atenção redobrada quanto a sua irrigação, pois o estresse 
hídrico pode ocasionar rachaduras nas raízes, tornandoa imprópria para o comércio. Além das rachaduras a raiz pode apresentar isoporização, tornando-os esponjosos e insípidos, como precaução convém elevar o teor de água no solo e colhê-los antes de chegarem ao seu ápice produtivo.

Kano \& Fukuoka (1995), citados por Costa et al. (2006), relatam que durante o período de crescimento de rabanete japonês, temperaturas do solo acima de $30{ }^{\circ} \mathrm{C}$ favorecem a ocorrência de rachaduras externas nas raízes, devido à formação de lignina ao redor das células, induzidas pelo aquecimento. $\mathrm{O}$ desenvolvimento do rabanete se dá no outono-inverno, aceitando bem o clima frio e as geadas (Linhares et al., 2010). Para o desenvolvimento adequado das raízes do rabanete é aconselhável condições climáticas baixas e dias curtos, também chamado de fotoperíodo. No período que foi desenvolvido este estudo apresentou temperaturas altas e fotoperíodo prolongado o que também contribui para diminuição na qualidade das raízes.

O efeito residual é de suma importância nos sistemas orgânicos de produção, principalmente em favorecer cultivos sucessivos, diminuindo desta forma os custos de produção nesse sistema aonde a aquisição de matérias se torna escassa em função da pouca disponibilidade de recurso dos produtores (Oliveira et al., 2005).

As fontes residuais dos adubos orgânicos utilizados (esterco bovino, cama de frango, cama de suíno) pouco contribuíram o desenvolvimento das plantas de rabanete na classe de solo estudada, ocasionando falta de resposta sobre as produtividades total e comercial, e seus efeitos sobre a qualidade são dependentes da interação entre a qualidade e quantidade das fontes residuais e condições climáticas.

\section{CONCLUSÕES}

O efeito residual de diferentes fontes de adubos orgânicos não foi satisfatório para a produção de rabanete em cultivo sucessivo de alface;

As raízes das cultivares de rabanete estudas não apresentaram padrões para comercialização;

O residual com adubação de 60 t/ha de esterco bovino foi o que apresentou melhores resultados para a qualidade das raízes;

Para cultivo de rabanete há necessidade da realização de nova adubação orgânica.

\section{LITERATURA CITADA}

ALVARES, C.C.; STAPE, J.L.; SENTELHAS, P.C. et al. Köppen's climate classification map for Brazil. Meteorologische Zeitschrift, v.22, n.6, p.711-728, 2013.

ALVAREZ VENEGAS, V.H.; RIBEIRO, A.C. Calagem. In: RIBEIRO, A.C.; UIMARÃES, P.T.G.; ALVAREZ VENEGAS, V.H. (Ed.).

Recomendações para o uso de corretivos e fertilizantes em Minas Gerais: 5 aproximação. Viçosa: Imprensa Universitária, 1999. p.43-60.

BONELA, G.D.; SOUZA, H.O.; GUIMARÃES, R.R. et al. Resposta de cultivares de alface a diferentes fontes de matéria orgânica. Revista Brasileira de Agropecuária Sustentável (RBAS), Viçosa, v.5, n.2, p. 89-95, 2015.

BRITO, O.R.; VENDRAME, P.R.S.; BRITO, R.M. Alterações das propriedades químicas de um Latossolo Vermelho distroférrico submetido a tratamentos com resíduos orgânicos. Semina:

Ciências Agrárias, Londrina, v.26, n.1, p.33-40, 2005.

CARDOSO, A.I.I.; HIRAKI, H. Avaliação de doses e épocas de aplicação de nitrato de cálcio em cobertura na cultura do rabanete. Horticultura Brasileira, Brasília, v.19, p.328-331, 2001.

CECCONELLO, S.T.; CENTENO, L.N. Avaliação de diferentes dosagens de vermicomposto produzido a partir de frutas, legumes e verduras na produção de rabanete (Raphanus sativus L.).

Revista Thema, Pelotas, v.13, n.1, p.93-102, 2016.

COSTA, C.C.; OLIVEIRA, C.D.; SILVA, C.J. et al. Crescimento, produtividade e qualidade de raízes de rabanete cultivadas sob diferentes fontes e doses de adubos orgânicos. Horticultura

Brasileira, Brasília, v.24, p.118-122, 2006.

EMPRESA BRASILEIRA DE PESQUISA AGROPECUÁRIA (EMBRAPA). Sistema Brasileiro de Classificação de Solos. Brasília: Embrapa, 2013. 353p.

FILGUEIRA, F.A.R. Novo manual de olericultura: agrotecnologia moderna na produção e comercialização de hortaliças. Viçosa, UFV, 2008. 421p. 
INMET: Instituto Nacional de Meteorologia. 2016. In: Http://www.inmet.gov.br/portal/

index.php?r=home/

page $\&$ page $=$ rede_estacoes_conv_graf. (Acessado em 24 março de 2016).

KANO, Y.; FUKUOKA, N. Effects of soil temperature on hollowness in Japanese radish (Raphanus sativus L. cv. 'Gensuke'). Scientia Horticulturae, v.6, p.157-166, 1995.

LINHARES, P.C.F.; PEREIRA, M.F.S.; PAZ, A.E.S. et al. Efeito residual de espécies espontâneas da caatinga no desempenho agronômico do coentro. Cadernos de Agroecologia, Cruz das Almas, v.6, n.2, p.1-5, 2011.

LINHARES, P.C.F. et al. Produtividade de rabanete em sistema orgânico de produção. Revista Brasileira de Gestão Ambiental, Mossoró, v.5, n.5, p.94-101, 2011.

LINHARES, P.C.F.; PEREIRA, M.F.S.; OLIVEIRA, B.S. et al. Produtividade de rabanete em sistema orgânico de produção. Revista Verde, Mossoró, v.5, n.5, p.94-101, 2010.

MAIA FILHO, F.C.F.; MESQUITA, E.F.; MELO, D.S. et al. Desenvolvimento fisiológico do gergelim BRS seda sob cultivo orgânico. Anais... Campina Grande, Embrapa Algodão, 2010. p.616-621.

MATOS, R.M.; SILVA, P.F.; LIMA, S.C. et al. Partição de assimilados em plantas de rabanete em função da qualidade da água de irrigação. Journal of Agronomic Sciences, v.4, n.1, p.151-164, 2015.

OLIVEIRA, A.K.; LIMA, J.S.S.; BEZERRA, A.M.A. et al. Produção de rabanete sob o efeito residual da adubação verde no consórcio de beterraba e rúcula. Revista Verde, Pombal, v.10, n.5, p.98-102, 2015.

OLIVEIRA, A.P.G.; GANDINE, S.M.S.; SABINO, S.M. et al. Potencialidade do uso de substrato organomineral no desenvolvimento de rabanete. Enciclopédia Biosfera, Goiânia, v.11, n.22, p.173, 2015.

OLIVEIRA, F.R.A. Interação entre salinidade e fósforo na cultura do rabanete. Revista Ciência Agronômica, Fortaleza, v.41, n.4, p.519-526, 2010.
OLIVEIRA, F.L.; RIBAS, R.G.T.; JUNQUEIRA, R.M. et al. Desempenho do consórcio entre repolho e rabanete com pré-cultivo de crotalária, sob manejo orgânico. Horticultura Brasileira, Seropédica, v.23, n.2, p.184-188, 2005.

PAIVA, A.C.C; LINHARES, P.C.F; MARACAJÁ, P.B. et al. Rabanete (Raphanus sativus L.) em sucessão aos cultivos de cenoura e coentro em sistema orgânico de produção. Revista Agropecuária Científica no Semiárido, Campina Grande, v.9, n.1, p.89-93, 2013.

PEDÓ, T.; LOPES, N.F.; MORAES, D.N. et al. Crescimento de três cultivares de rabanete (Raphanus sativus) ao longo da ontogenia das plantas. Tecnologia \& Ciência Agropecuária, João Pessoa, v.4, n.3, p.17-21, 2010.

PEIXOTO FILHO, J.U.; FREIRE, M.B.G.S.; FREIRE, F.J. et al. Produtividade de alface com doses de esterco de frango, bovino e ovino em cultivos sucessivos. Revista Brasileira de Engenharia Agrícola e Ambiental, Campina Grande, v.17, n.4, p.419-424, 2013.

PEREIRA, M.F.S.; LINHARES, P.C.F.; MARACAJÁ, P.B. et al. Desempenho agronômico de cultivares de coentro (Coriandrum sativum L.) fertilizado com composto de algodão. Revista Verde de Agroecologia e Desenvolvimento Sustentável, Mossoró, v.6, n.2, p.07-12, 2011.

PERIN, A.; SANTOS, R.H.S.; URQUIAGA, S. et al. Efeito residual da adubação verde no rendimento de brócolo (Brassica oleraceae L. var. italica) cultivado em rotação de culturas com milho. Ciência Rural, Santa Maria, v.34, n.6, p.1739-1745, 2004.

PINHEIRO, R.R. et al. Emergência do rabanete em diferentes substratos. In: Seminário

Interenstitucional de ensino, pesquisa e extensão, 2012. Anais... Cruz Alta-RS: XVII SIEPE, 2012.

PULITI, J.P.M.; REIS, H.B.; PAULINO, H.D.M. et al. Comportamento da cultura do rabanete em função de fontes e doses de cálcio.

Horticultura Brasileira, Brasília, v.27, p.3003-3008, 2009.

RODRIGUES, J.F.; REIS, J.M.R.; REIS, M.A. Utilização de estercos em substituição a adubação mineral na cultura do rabanete. Revista

Trópica: Ciências Agrárias e Biológicas, Maranhão, v.7, n.2, p.160-168, 2013. 
SALGADO, A.S.; GUERRA, J.G.M.; ALMEIDA, D.L. et al. Consórcios alface-cenoura e alfacerabanete sob manejo orgânico. Pesquisa

Agropecuária Brasileira, Brasília, v.41, n.7, p.1141-1147, 2006.

SILVA, A.F.A.; SOUZA, E.G.F.; BARROS JÚNIOR, A.P. et al. Desempenho agronômico do rabanete adubado com Calotropis procera (Ait.) R. Br. em duas épocas de cultivo. Revista Ciência

Agronômica, Fortaleza, v.48, n.2, p.328-336, 2017.
SOUZA, M.D.B.; NASCIMENTO, A.D.; RAMOS, A.B. Produção orgânica de rabanete sob diferentes fontes de adubos orgânicos. In: Seminário de Agroecologia de Mato Grosso do Sul. Cadernos de Agroecologia, v.7, n.2, 2012.

VITTIL, M.R.; VIDAL, M.B.; MORSELLI, T.B.G.A. et al. Resposta do rabanete a adubação orgânica em ambiente protegido. Revista Brasileira de Agroecologia, Curitiba, v.2, n.1, p.45-53, 2007.

Recebido para publicação em 3/3/2017 e aprovado em 31/5/2017. 